\title{
Dyslipidemia in Patients with Coronary Heart Disease and Cardiovascular Disease Risk Stratified Filtering
}

\author{
Chunhua $\mathrm{Ma}^{1,2, *}$ \\ ${ }^{1}$ Eastern Liaoning University, Dandong 118003, China \\ ${ }^{2}$ Xuanwu Hospital, Capital Medical University,Beijing 100053, China \\ ${ }^{*}$ Corresponding author
}

\begin{abstract}
Dyslipidemia AS one of the most important risk factors, with a variety of CAD and other AS sex of CVD occurrence is closely related to the oxidation of lipoprotein also plays a key role in the patients. A large number of research confirmed that high. X - LDL and ox - Lp (a) level is AS strong risk factors, can be used AS a CAD diagnosis especially effective index of the differential diagnosis of ACS. Micronics AS a kind of about 19 to 24 nuclear acid's long no coding single small RNA molecules that control gene expression in the translation level for. Macrons with high tissue specificity, but due to the organization based the inconvenience, are limited in clinical application, by contrast, serum or plasma microns' high stability, specificity, and conveniently, is expected to become a new diagnosis of the related diseases.. In recent years, the study found the miRNA and cardiovascular system development, differentiation and AS CVD is closely related to the occurrence and development of all, it may be involved in regulation of the variety of the AS related path physiological process; serum or blood macrons are expected to be CAD of effective molecular markers, and. X - LDL, ox - Lp (a) the common application in clinical diagnosis, condition monitoring and prognosis judgments of $\mathrm{CAD}$, and achieve early identification and diagnosis of ACS.
\end{abstract}

Keywords-coronary heart disease; cardiovascular disease (CVD); dyslipidemia; microns; screening

\section{INTRODUCTION}

Containing a high incidence of CVD risk stratification is the key to the crowd as soon as possible to implement effective interventions, and accurately identify and diagnose different CV D level of risk is the necessary premise that clinical relevant prevention and control work. However, although at present already had a lot of the show CAD patients with normal serum or plasma miRNA expression exists obvious difference[1,2], and is expected to become a new diagnostic marker of the CAD especially ACS, but the risk stratification of CVD dyslipidemia crowd serum or plasma miRNA expression spectrum research has not yet been reported, and serum or plasma micrograms with severity AS lesions, the relationship between lipid metabolic disorder is not yet clear. Therefore, screening of different CVD risk stratification dyslipidemia crowd serum specific miRNA expression, and further explore serum macrons and AS disease severity, the relationship between lipid metabolic disorders[3,4], accurate to evaluate its clinical value, will be conducive to clinical identification and diagnosis of different CVD risk level of the crowd, and CV D especially early prevention and treatment of acute CVD events is of great significance, AS well AS specific serum micrograms in mechanism AS the role of CVD occurrence, development and provides a new train of thought with clues.

\section{THE CALCULATION OF CORONARY ARTERY LESION SEVERITY GEMINI SCORE}

According to the risk stratification of CV D high-risk groups (including a group of patients with ACS and SCAD) results of coronary angiography by using modified Gemini score [5], a quantitative assessment according to the degree of coronary artery disease: (1) the first according to the stenos is of coronary artery lesions with basic score: narrow is less than or equal to $25 \% 1$ minute, stenos is $26 \%$ to $50 \% 2$ points, stenos is $51 \%$ to $75 \%$ as 4 points, stenos is $76 \%$ to $90 \%$ of eight points, stenos is $91 \%$ to $99 \%$ of 16 points, narrow $100 \%$ is totally occluded meter 32 points;(2) according to coronary artery lesions of parts to determine the scale coefficient, the coronary artery lesions with narrow score multiplied by the corresponding coefficient of different segments: namely the pathological changes of the segmental integral coefficient of left coronary artery of 5; Left anterior descending branch recently coefficient is 2.5 , the middle coefficient is 1.0 , far end coefficient for I, the first and the second diagonal branch coefficient is 1 ;Left circumflex branch opening coefficient is 3.5 , the recent coefficient is 2.5 , far end coefficient is I, with a blunt edge and descending branch coefficients for the I; Left ventricular side branch coefficient is 0.5 ;Near, far of right coronary artery and descending branch coefficients for the I;(3) the final points of the coronary artery lesions for different segmental integral sum.

\section{THE DATA ANALYSIS}

Data analysis by SPSS 16.0 software. Data to mean and standard error. Analysis before each data to Kolmogorov Smirnov has - to test its distribution characteristics, sleekness again after logarithmic transformation and data analysis. Normal distribution data comparison between the two groups using two sets of independent sample t-test; Multiple sets of comparison between the single factor analysis of variance[6]. Sleekness distribution data is compared between groups use Krystal Wallis $\mathrm{H}$ rank and inspection. Correlation between variables by Spearman correlation analysis.: difference was statistically significant $(\mathrm{P}<0.05)$.

\section{The OBJECT OF STUdy Of ClinicAl BASIC INFORMATION}

CVD risk stratification in this study the high-risk groups, 
including a group of patients with ACS and SCAD, moderate, low-risk group and normal control group clinical basic information, as shown in table I. Each group of age, sex and body mass index had no significant difference $(\mathrm{P}>0.05)$.

TABLE I. THE CLINICAL BASIC INFORMATION

\begin{tabular}{|c|c|c|c|c|c|}
\hline \multirow{2}{*}{ Groups } & \multicolumn{2}{|c|}{ High risk HB } & \multirow{2}{*}{$\begin{array}{c}\text { average } \\
\text { risk } \\
\text { group }\end{array}$} & \multirow{2}{*}{$\begin{array}{c}\text { low-risk } \\
\text { group }\end{array}$} & \multirow{2}{*}{ WKY } \\
\hline & ACS & SCAD & & & \\
\hline NNT & 89 & 86 & 40 & 112 & 103 \\
\hline Age & $\begin{array}{c}64.77 \pm \\
1.47\end{array}$ & $\begin{array}{c}62.47 \\
\pm 1.29\end{array}$ & $\begin{array}{c}57.6912 \\
.93\end{array}$ & $\begin{array}{c}60.04 \text { 士 } \\
1.29\end{array}$ & $\begin{array}{c}61.93 \pm \\
1.63\end{array}$ \\
\hline $\begin{array}{c}\text { Gender } \\
\text { (male/fe } \\
\text { male) }\end{array}$ & $66 / 23$ & $53 / 33$ & $31 / 9$ & $73 / 29$ & $73 / 30$ \\
\hline $\begin{array}{l}\text { BMI } \\
((\mathrm{kg} / \\
\mathrm{m} 3) \\
\end{array}$ & $\begin{array}{c}26.11 \\
\pm 0.36\end{array}$ & $\begin{array}{c}25.7610 \\
.42\end{array}$ & $\begin{array}{c}26.09 \\
\pm 0.38\end{array}$ & $\begin{array}{c}24.28 \text { 士 } \\
0.20\end{array}$ & $\begin{array}{c}23.70 \text { 士 } \\
0.19\end{array}$ \\
\hline Smoke & 32 & 30 & 15 & 40 & 22 \\
\hline $\begin{array}{l}\text { hypertens } \\
\text { ion }\end{array}$ & 45 & 43 & 40 & 9 & 0 \\
\hline diabetes & 18 & 14 & 0 & 0 & 0 \\
\hline
\end{tabular}

Note: adopt single because of poor Scoffing analysis is compared between groups, $\mathrm{P}<0.05$ for the difference was statistically significant.

Used for low density chip detection of serum RNA extraction results Will be in accordance with the method of the extracted four groups (including the ACS group, SCAD, low-risk group and normal control group), serum total RNA using DEP (water dissolves adequately, use spectrophotometer to determine the concentration of RNA (unit: p6 small 1), the purity of $260 \mathrm{~nm}$ and $280 \mathrm{DM}$ absorbance (optical density, OD) said the ratio of the value (that is, the OD $260 \mathrm{~nm} / \mathrm{OD} 280 \mathrm{nn}$ ), the results showed: the RNA content of the proposed four groups mixed serum samples were completely accord with the requirement of TLDA detection (see table 2).

\section{The VERIFICATION RESUlts OF SERUM SPECIFIC MARINAS}

Based on the compound sieve experiment results in the small batch samples, using rt-pcr and qRT - in a large number of PCR technology volume of the sample verification, namely, respectively, 175 cases of CV risk stratification D high-risk group of patients (including 89 patients with ACS group and SCAD group of patients, 86 cases), 112 cases, 40 cases in the intermediate risk category had a low-risk group and 103 cases of normal control group of serum miR - 208 - b, miR - 499, miR - 186 and miR - 146 - a expression level, the results with Ct value, has - let - 7 D/g/I for internal, ACS, SCAD, medium and low risk group relatively normal serum macrons change ratio is adopted in the control group 2 - delta said Ct (delta Ct $=$ CtmiRNA Ctlet_7d/p/I, and delta CtmiRNA a delta Ct normal controls) are shown in table 2.
TABLE II. FOUR GROUPS OF MIXED SERUM RNA EXTRACTION

\begin{tabular}{|c|c|c|c|c|}
\hline \multirow{2}{*}{ Groups } & \multicolumn{2}{|c|}{ High risk HB } & \multirow{2}{*}{$\begin{array}{l}\text { low-risk } \\
\text { group } \\
N=50\end{array}$} & \multirow{2}{*}{$\begin{array}{l}W K Y \\
N=50\end{array}$} \\
\hline & $\begin{array}{c}A C S \\
N=50\end{array}$ & $\begin{array}{l}S C A D \\
N=50\end{array}$ & & \\
\hline $\begin{array}{l}\text { Concentr-a } \\
\text { tion(ug/ul) }\end{array}$ & 0.32 & 0.17 & 0.42 & 0.27 \\
\hline $\begin{array}{l}\text { Volume } \\
\text { (ul) }\end{array}$ & 20 & 20 & 20 & 20 \\
\hline Gross(ug) & 6.40 & 3.40 & 8.40 & 5.40 \\
\hline $\begin{array}{l}\text { OD260nm/ } \\
\text { OD260nm }\end{array}$ & 1.55 & 1.45 & 1.53 & 1.50 \\
\hline
\end{tabular}

Verify the experimental results shows that:

(1) Compared with normal control group, the risk stratification of VD high-risk groups (including the ACS group and SCAD), moderate and low risk group of serum miR - 208 b, miR - 186, miR - 146 - a expression levels were significantly higher $(\mathrm{P}<0.05)$ : in the high-risk groups, and the expression level of serum $\mathrm{miR}$ - 499 crisis group were significantly increased $(\mathrm{P}<0.05)$.

(2) In the risk stratification of VD C in all groups, high-risk group and moderate group serum miR - 208 - b, MiR - 499, miR - 186 expression level was significantly higher than in low-risk group (I - spoon. UD).

(3) In patients with CVD risk stratification of high-risk groups, the ACS group of patients with serum miR - 499, miR - 186 expression levels were significantly higher (SCAD group patients $(\mathrm{P}<0.05)$; the expression level of serum miR - 186 in patients with ACS group and also significantly higher than in the intermediate risk category had a low-risk group $((\mathrm{P}<0.05)$; the patients with ACS and SCAD group serum miR - $208-b$, miR - 499 expression level was also significantly higher than low-risk group ( $(\mathrm{P}<0.05)$.Serum miR - 208 - b, miR - 499, $\mathrm{miR}-186$ and $\mathrm{miR}$ - 146 - a in expression level between the groups as shown in figure 1 , figure 2, figure 3 and figure 4 .

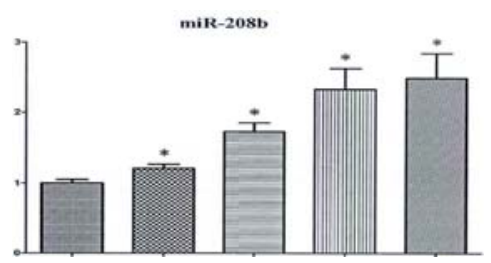

FIGURE I. ALL THE EXPRESSION LEVEL OF SERUM MIR - 208 - B IN THE OBJECT OF STUDY

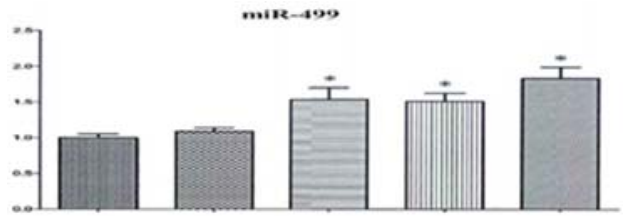

FIGURE II. THE EXPRESSION LEVEL OF SERUM MIR - 499 IN ALL SUBJECTS 


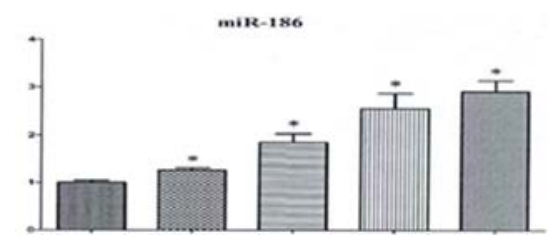

FIGURE III. THE EXPRESSION LEVEL OF SERUM MIR - 186 IN ALL SUBJECTS

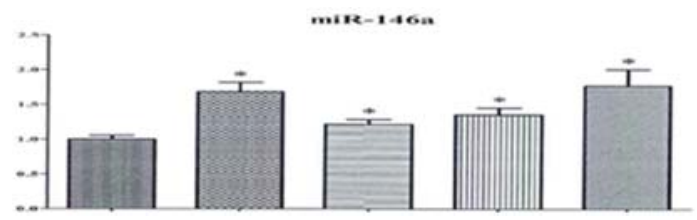

FIGURE IV. ALL THE EXPRESSION LEVEL OF SERUM MIR - 146 - A IN THE OBJECT OF STUDY

$\mathrm{X}$ axis, normal control group low-risk group in the risk scad group acd group Y axis, relative to the let $-7 \mathrm{~d} / \mathrm{g} / \mathrm{i}$ change

Note: * as compared with normal control group, $\mathrm{P}<0.05$

\section{CONCLUSION}

To sum up, at high risk of developing CVD risk stratification (including patients with ACS and SCAD), moderate and low risk population are very stable expression in specific serum micrograms in serum; Serum miR - 208 - b, miR - 499, miR - 186, miR - 146 - a can be used as identification CVD risk stratification[7], moderate and low risk population at risk effective biomarkers, CVD risk comprehensive assessment and layered; Serum miR - 499 and miR - 186 can be used as effective indexes of patients with ACS and SCAD differential diagnosis; Serum miR - 208 - b, miR - 499 and miR - 186 can be reflected AS the severity of CVD lesions, closely related with lipid metabolism disorders. Therefore, serum miR - 208 - b, miR - 499, miR - 186 and miR - 146 - a change of expression level not only can be used as a new CAD especially ACS diagnosis biomarkers [8], and hopefully for different CVD risk comprehensive assessment and layered provides new ways and methods, is helpful for the early work of clinical prevention and control of CVD, effectively reduce the incidence, morbidity and mortality of CVD.

\section{REFERENCE}

[1] GUO M, MAO X, JI Q, et al.miR-146ain PBMCs modulates Th1function in patients with acute coro-nary syndrome. Immunology and Cell Biology. 2010

[2] Bernard R, Corday E, Eliiash H, et al. Nomenclature and criteria for diagnosis of ischemic heart disease. Circulation 1979

[3] Heart Protection Study Collaborative Group MRC/BHF Heart Protection Study of cholesterol lowering with simvastatin in 20,536 high-risk individuals: a randomised placebo-controlled trial. Lancet, The 2002

[4] Hoff HF, O’Neil J, Yashiro A. Partial characterization of lipoproteins containing apo (a) in human atherosclerotic lesions. Journal of Lipid Research. 1993

[5] Holvoet P, Collen D. Oxidation of low density lipoproteins in the pathogenesis of atherosclerosis. Atherosclerosis 1998

[6] Stocker R, Keaney JF Jr. Role of oxidative modifications in atherosclerosis. Physiological Reviews. 2004

[7] Wilson P D, Agostino R Levy D, et al. Prediction of coronary heart disease using risk factor categories. Circulation. 1998
[8] D' Agostino RB, Grundy S, Sullivan LM, et al. Validation of the Framingham coronary heart disease prediction scores: results of a multiple ethnic groups investigation. Journal of the American Medical Association, The. 2001. 